\title{
LASERTERAPIA NA INFLAMAÇÃO PULMONAR EXPERIMENTAL EM RATTUS NORVEGICUS OCASIONADO PELA PAPAÍNA
}

\author{
Diego Rodrigues Pessoa' \\ Khetyma Moreira Fonseca ${ }^{2}$ \\ Erik Vinicius de Sousa Reis ${ }^{3}$ \\ Jose Lopes Pereira Junior ${ }^{4}$ \\ Wellington dos Santos Alves ${ }^{5}$
}

Resumo: A Doença Pulmonar Obstrutiva Crônica (DPOC) é caracterizada pela limitação do fluxo aéreo decorrente da dilatação dos espaços aéreos distais aos bronquíolos terminais. Analisar os efeitos da laserterapia quanto ao processo cicatricial na lesão pulmonar experimental em Rattus Novergicus. Utilizaram-se trinta animais agrupados em três grupos de dez animais: grupo controle (GC) (não recebeu nada), grupo DPOC (GD) (foi pulverizado 3 doses de papaína 3mg/kg) e grupo DPOC + Laser (GDL) (após 7 dias da indução da lesão com papaína foi tratado com laser de $660 \mathrm{~nm}$ durante 15 dias). Para analise dos resultados foi realizado o lavado broncoalveolar. Quanto ao Lavado: GC (número de células normais), GD (aumento de células inflamatórias) e GDL (diminuição de células inflamatórias). A laserterapia diminui o numero de células inflamatórias, entretanto, não possui efeito reconstrutor do parênquima pulmonar apenas estabiliza a lesão comprovando sua ação anti-inflamatória.

Palavras-chave: Modelos animais; Enfisema; Papaína; Terapia a laser de Baixa Intensidade.

\footnotetext{
1 Centro de Laserterapia e Fotobiologia - CELAFO/Instituto de Pesquisa e Desenvolvimento/Universidade do Vale do Paraíba (UNIVAP), Brasil. E-mail: fisio.diegorodrigues@gmail.com.

2 Graduanda em Fisioterapia, Universidade Estadual do Piauí (UESPI), Teresina/Piauí, Brasil. E-mail: khetyma_mf@hotmail.com.

3 Graduado em Biomedicina, Universidade Federal do Piauí (UFPI), Teresina/Piauí, Brasil. E-mail: reis.erik@gmail.com.

4 Graduado em Ciências Farmacêuticas, Faculdade Santo Agostinho (FSA), Teresina/Piauí, Brasil. E-mail: juniorlopes@hotmail.com.

${ }^{5}$ Doutor em Engenharia da Reabilitação (UNINOVE), Faculdade Santo Agostinho (FSA) Teresina/Piauí, Brasil. Email: wellingtonsa74@hotmail.com.
} 